\title{
Iterative algorithms for common elements in fixed point sets and zero point sets with applications
}

Mingliang Zhang

\author{
Correspondence: zhangml@henu. \\ educn \\ School of Mathematics and \\ Information Sciences, Henan \\ University, Kaifeng 475000, China
}

\begin{abstract}
In this study, Mann-type iterative process is considered for finding a common element in the fixed point set of strict pseudocontractions and in the zero point set of the operator which is the sum of inverse strongly- monotone operators and maximal monotone operators. Weak convergence theorems of common elements are established in the framework of Hilbert spaces. Some applications of main results are also provided.

AMS Subject Classification: 47H05; 47H09; 47J25; $90 \mathrm{C33.}$

Keywords: equilibrium problem, variational inequality, strictly pseudocontractive mapping, nonexpansive mapping, inverse-strongly monotone mapping
\end{abstract}

\section{Introduction and preliminaries}

Throughout this article, we always assume that $H$ is a real Hilbert space with the inner product $\langle\cdot, \cdot\rangle$, and the norm $\|\cdot\|$ and that $C$ is a nonempty closed convex subset of $H$.

Let $A: C \rightarrow H$ be a mapping. Recall that $A$ is said to be monotone if

$$
\langle A x-A y, x-y\rangle \geq 0, \forall x, y \in C \text {. }
$$

$A$ is said to be inverse strongly-monotone if there exists a constant $\alpha>0$ such that

$$
\langle A x-A y, x-y\rangle \geq \alpha\|A x-A y\|^{2}, \quad \forall x, y \in C .
$$

For such a case, $A$ is also said to be $\alpha$-inverse strongly monotone.

Let $M: H \rightarrow 2^{H}$ be a set-valued mapping. The set $D(M)$ defined by $D(M)=\{x \in H$ : $M x \neq \varnothing\}$ is said to be the domain of $M$. The set $R(M)$ defined by $R(M)=\bigcup_{x \in H} M x$ is said to be the range of $M$. The set $G(M)$ defined by $G(M)=\{(x, y) \in H \times H: x \in D$ $(M), y \in R(M)\}$ is said to be the graph of $M$.

Recall that $M$ is said to be monotone if

$$
\langle x-y, f-g\rangle \geq 0, \quad \forall(x, f),(y, g) \in G(M) .
$$

$M$ is said to be maximal monotone if it is not properly contained in any other monotone operator. Equivalently, $M$ is maximal monotone if $R(I+r M)=H$ for all $r>0$. The class of monotone mappings is one of the most important classes of mappings. Within the past several decades, many authors have been devoting to the studies on the

(c) 2012 Zhang; licensee Springer. This is an Open Access article distributed under the terms of the Creative Commons Attribution License (http://creativecommons.org/licenses/by/2.0), which permits unrestricted use, distribution, and reproduction in any medium, provided the original work is properly cited. 
existence and convergence of zero points for maximal monotone mappings, see [1-15] and the references therein. For a maximal monotone operator $M$ on $H$ and $r>0$, we may define the single-valued resolvent $J_{\mathrm{r}}=(I+r M)^{-1}: H \rightarrow D(M)$. It is known that $J_{r}$ is firmly nonexpansive and $M^{-1}(0)=F\left(J_{r}\right)$, where $F\left(J_{r}\right)$ denotes the fixed point set of $J_{r}$.

Let $S: C \rightarrow C$ be a nonlinear mapping. In this study, we use $F(S)$ to denote the fixed point set of $S$. Recall that the mapping $S$ is said to be nonexpansive if

$$
\|S x-S y\| \leq\|x-y\|, \quad \forall x, y \in C .
$$

$S$ is said to be $\kappa$-strictly pseudocontractive if there exists a constant $\kappa \in[0,1)$ such that

$$
\|S x-S y\|^{2} \leq\|x-y\|^{2}+\kappa\|(x-S x)-(y-S y)\|^{2}, \quad \forall x, y \in C .
$$

The class of strictly pseudocontractive mappings was introduced by Browder and Petryshyn [16]. If $\kappa=0$, the class of strictly pseudocontractive mappings is reduced to the class of nonexpansive mappings. In case that $\kappa=1$, we call $S$ a pseudocontractive mapping. Marino and $\mathrm{Xu}$ [17] proved that fixed point sets of strictly pseudocontractive mappings are closed and convex. They also proved that $I-S$ is demi-closed at zero. To be more precise, if $\left\{x_{n}\right\}$ is a sequence in $C$ with $x_{n} \rightarrow x$ and $x_{n}-S x_{n} \rightarrow 0$, then $x \in$ $F(S)$.

Let $A: C \rightarrow H$ be an inverse strongly-monotone mapping. Recall that the classical variational inequality problem is to find $x \in C$ such that

$$
\langle A x, y-x\rangle \geq 0, \quad \forall y \in C .
$$

Denote by $\operatorname{VI}(C, A)$ of the solution set of (1.1). It is known that $x \in C$ is a solution to (1.1) if and only if $x$ is a fixed point of the mapping $P_{C}(I-\lambda A)$, where $\lambda>0$ is a constant and $I$ is the identity mapping. In [3], Iiduka and Takahashi showed that if $\lambda$ $\in[0,2 \alpha]$, then $I-\lambda A$ is nonexpansive.

Let $F$ be a bifunction from $C \times C$ to $\mathbb{R}$, where $\mathbb{R}$ denotes the set of real numbers. Recall the following equilibrium problem.

$$
\text { Find } x \in C \text { such that } F(x, y) \geq 0, \forall y \in C \text {. }
$$

To study the equilibrium problems (1.2), we may assume that $F$ satisfies the following conditions:

(A1) $F(x, x)=0$ for all $x \in C$;

(A2) $F$ is monotone, i.e., $F(x, y)+F(y, x) \leq 0$ for all $x, y \in C$;

(A3) for each $x, y, z \in C$,

$$
\lim _{t \downarrow 0} \sup F(t z+(1-t) x, y) \leq F(x, y) ;
$$

(A4) for each $x \in C, y \mapsto F(x, y)$ is convex and lower semi-continuous.

Putting $F(x, y)=\langle A x, y-x\rangle$ for every $x, y \in C$, we see that the equilibrium problem (1.2) is reduced to the variational inequality (1.1). 
Recently, many authors considered the convergence of iterative sequences for the variational inequality (1.1), the equilibrium problem (1.2) and fixed point problems of nonlinear mappings; see, for example, [2,4-7,11-15,18-26].

In 2003, Takahashi and Toyoda [13] proved the following weak convergence theorem.

Theorem 1.1. Let $C$ be a closed convex subset of a real Hilbert space H. Let $A$ be an $\alpha$-inverse strongly-monotone mapping from $C$ into $H$ and $S$ be a non-expansive mapping from $C$ into itself such that $F(S) \cap V I(C, A) \neq \varnothing$. Let $\left\{x_{n}\right\}$ be a sequence generated by

$$
x_{0} \in C, x_{n+1}=\alpha_{n} x_{n}+\left(1-\alpha_{n}\right) S P_{C}\left(x_{n}-\lambda_{n} A x_{n}\right), \quad \forall n \geq 0,
$$

where $\lambda_{n} \in[\mathrm{a}, \mathrm{b}]$ for some $a, b \in(0,2 \alpha)$ and $\alpha_{n} \in[\mathrm{c}, \mathrm{d}]$ for some $c, d \in(0,1)$. Then, $\left\{x_{n}\right\}$ converges weakly to $z \in F(S) \cap V I(C, A)$, where $z=\lim _{n \rightarrow \infty} P_{F(S) \cap V I}(C, A) x_{n}$.

In 2007, Tada and Takahashi [11] obtained the following weak convergence theorem.

Theorem 1.2. Let $C$ be a nonempty closed convex subset of a real Hilbert space $H$. Let $F$ be a bifunction from $C \times C$ to $\mathbb{R}$ satisfying (A1)-(A4) and $S$ be a nonexpansive mapping from $C$ into $H$ such that $F(S) \cap E P(F) \neq \varnothing$. Let $\left\{x_{n}\right\}$ and $\left\{u_{n}\right\}$ be sequences generated by $x_{1}=x \in H$ and let

$$
\left\{\begin{array}{l}
u_{n} \in C \text { such that } F\left(u_{n}, u\right)+\frac{1}{r_{n}}\left\langle u-u_{n}, u_{n}-x_{n}\right\rangle \geq 0, \forall u \in C, \\
x_{n+1}=\alpha_{n} x_{n}+\left(1-\alpha_{n}\right) S u_{n}
\end{array}\right.
$$

for each $n \geq 1$, where $\left\{\alpha_{n}\right\} \subset[\mathrm{a}, \mathrm{b}]$ for some $a, b \in(0,1)$ and $\left\{r_{n}\right\} \subset(0, \infty)$ satisfies $\lim \inf _{n \rightarrow \infty} r_{n}>0$. Then, $\left\{x_{n}\right\}$ converges weakly to $w \in F(S) \cap E P(F)$ where $w=\lim _{n \rightarrow \infty} P_{F}$ $(S) \cap E P(F) x_{n}$.

A very common problem in diverse areas of mathematics and physical sciences consists of trying to find a point in the intersection of convex sets. This problem is referred to as the convex feasibility problem; its precise mathematical formulation is as follows. Find an $x \in \bigcap_{m=1}^{N} C_{r}$, where $N \geq 1$ is an integer and each $C_{m}$ is a nonempty closed convex subset of $H$. There is a considerable investigation on the convex feasibility problem in the setting of Hilbert spaces which captures applications in various disciplines such as image restoration, computer tomography, and radiation therapy treatment planning.

Let $K$ be an integer, $S: C \rightarrow C$ a strict pseudocontraction, $A_{m}: C \rightarrow H$ be an $\alpha_{m^{-}}$ inverse strongly-monotone mapping and $M_{m}: H \rightarrow 2^{H}$ be a maximal monotone operator such that $D\left(M_{m}\right) \subset C$, where $D\left(M_{m}\right)$ is the domain of $M_{m}$, where $m \in\{1,2, \ldots, K\}$. In this article, motivated by Theorems 1.1 and 1.2, we consider the problem of finding a common element in the following set: $F(S) \cap \bigcap_{m=1}^{K}\left(A_{m}+M_{m}\right)^{-1}(0)$, where $F(S)$ is the fixed point set of $S$ and $\left(A_{m}+M_{m}\right)^{-1}(0)$ is the zero point set of $A_{m}+M_{m}$. Weak convergence theorems of common elements are established in real Hilbert spaces. The results presented in this article improve and extend the corresponding results announced by Tada and Takahashi [11] and Takahshi and Toyoda [13].

In order to prove our main results, we also need the following lemmas.

Lemma 1.3. [16] Let $C$ be a nonempty closed convex subset of a real Hilbert space $H$ and $S: C \rightarrow C$ be a $\kappa$-strict pseudo-contraction with a fixed point. Define $S: C \rightarrow C$ 
by $S_{a} x=a x+(1-a) S x$ for each $x L$. If $a \in[\kappa, 1)$, then $S_{a}$ is nonexpansive with $F\left(S_{a}\right)$ $=F(S)$.

Lemma 1.4. [17]Let $C$ be a nonempty closed convex subset of a real Hilbert space $H$ and $S: C \rightarrow C$ be a $\kappa$-strict pseudocontraction. Then

(a) $S$ is $\frac{1+\kappa}{1-\kappa}$-Lipschitz;

(b) $I-S$ is demi-closed, this is, if $\left\{x_{n}\right\}$ is a sequence in $C$ with $x_{n}-x$ and $x_{n}-S x_{n} \rightarrow$ 0 , then $x \in F(S)$.

Lemma 1.5. [27] Let $H$ be a real Hilbert space and $0<p \leq t_{n} \leq q<1$ for all $n \geq 1$. Suppose that $\left\{x_{n}\right\}$ and $\left\{y_{n}\right\}$ are sequences in $H$ such that

$$
\limsup _{n \rightarrow \infty}\left\|x_{n}\right\| \leq r, \quad \limsup _{n \rightarrow \infty}\left\|y_{n}\right\| \leq r
$$

and

$$
\lim _{n \rightarrow \infty}\left\|t_{n} x_{n}+\left(1-t_{n}\right) y_{n}\right\|=r
$$

hold for some $r \geq 0$. Then $\lim _{n \rightarrow \infty}\left\|x_{n}-y_{n}\right\|=0$.

Lemma 1.6. [13] Let $C$ be a nonempty closed convex subset of a real Hilbert space $H$ and $P_{C}$ be the metric projection from $H$ onto $C$. Let $\left\{x_{n}\right\}$ be a sequence in $H$. Suppose that, for all $y \in C$

$$
\left\|x_{n+1}-y\right\| \leq\left\|x_{n}-y\right\|, \quad \forall n \geq 1 .
$$

Then $\left\{P_{C} x_{n}\right\}$ converges strongly to some $z \in C$.

Lemma 1.7. [28] Let $C$ be a nonempty closed convex subset of a real Hilbert space $H$, $A: C \rightarrow H$ be a mapping and $M: H \rightarrow 2^{H}$ be a maximal monotone mapping. Then

$$
F\left(J_{r}(I-r A)\right)=(A+M)^{-1}(0), \quad \forall r>0 .
$$

Lemma 1.8. [29] Let $H$ be a Hilbert space and suppose $\left\{x_{n}\right\}$ converges weakly to $x$. Then

$$
\liminf _{n \rightarrow \infty}\left\|x_{n}-x\right\|<\lim _{n \rightarrow \infty} \inf \left\|x_{n}-y\right\|
$$

for all $y \in H$ with $x \neq y$.

\section{Main results}

Theorem 2.1. Let $C$ be a nonempty closed convex subset of a real Hilbert space H. Let $S: C \rightarrow C$ be a $\kappa$-strict pseudocontraction, $A: C \rightarrow H$ be an $\alpha$-inverse strongly monotone mapping and $B: C \rightarrow H$ be a $\beta$-inverse strongly monotone mapping. Let $M: H \rightarrow$ $2^{H}$ and $W: H \rightarrow 2^{H}$ be maximal monotone operators such that $D(M) \subset C$ and $D(W)$ C C. Assume that $\mathcal{F}:=F(S) \cap(A+M)^{-1}(0) \cap(B+W)^{-1}(0) \neq \emptyset$. Let $\left\{x_{n}\right\}$ be a sequence generated in the following manner:

$$
\left\{\begin{array}{l}
x_{0} \in C \\
y_{n}=\gamma_{n} J_{r_{n}}\left(x_{n}-r_{n} A x_{n}\right)+\left(1-\gamma_{n}\right) J_{s_{n}}\left(x_{n}-s_{n} B x_{n}\right), \\
x_{n+1}=\alpha_{n} x_{n}+\left(1-\alpha_{n}\right)\left(\beta_{n} y_{n}+\left(1-\beta_{n}\right) S y_{n}\right), \quad n \geq 0
\end{array}\right.
$$


where $J_{r_{n}}=\left(I+r_{n} M\right)^{-1}, J_{s_{n}}=\left(I+s_{n} W\right)^{-1},\left\{r_{n}\right\}$ is a sequence in $(0,2 \alpha)$, \{s $\}$ is a sequence in $(0,2 \beta)$ and $\left\{\alpha_{n}\right\},\left\{\beta_{n}\right\}$, and $\left\{\gamma_{n}\right\}$ are sequences in $(0,1)$. Assume that the following restrictions are satisfied

(a) $0<a \leq r_{n} \leq b<2 \alpha$ and $0<c \leq s_{n} \leq d<2 \beta$;

(b) $0 \leq \kappa \leq \beta_{n}<e<1,0<h \leq \alpha_{n} \leq i<1$ and $0<j \leq \gamma_{n} \leq k<1$,

where $a, b, c, d, e, h, i, j, k$ are real numbers. Then the sequence $\left\{x_{n}\right\}$ converges weakly to $\bar{x} \in \mathcal{F}$, where $\bar{x}=\lim _{n \rightarrow \infty} P_{\mathcal{F}} x_{n}$.

Proof. Note that $\left(I-r_{n} A\right)$ and $\left(I-s_{n} B\right)$ are nonexpansive for each fixed $n \geq 0$.

Indeed, for any $x, y, \in C$, we see from the restriction (a) that

$$
\begin{aligned}
\left\|\left(I-r_{n} A\right) x-\left(I-r_{n} A\right) y\right\|^{2} & =\|x-y\|^{2}-2 r_{n}\langle x-y, A x-A y\rangle+r_{n}^{2}\|A x-A y\|^{2} \\
& \leq\|x-y\|^{2}-r_{n}\left(2 \alpha-r_{n}\right)\|A x-A y\|^{2} \\
& \leq\|x-y\|^{2} .
\end{aligned}
$$

This shows that $\left(I-r_{n} A\right)$ is nonexpansive for each fixed $n \geq 0$, so is $\left(I-s_{n} B\right)$.

Put

$$
S_{n} x=\beta_{n} x+\left(1-\beta_{n}\right) S x, \quad \forall x \in C .
$$

In the restriction (b), we obtain from Lemma 1.3 that $S_{n}$ is nonexpansive for each fixed $n \geq 0$. Fixing $p \in \mathcal{F}$ and since $J_{r_{n}}, J_{s_{n}}, I-r_{n} A$, and $I-s_{n} B$ are nonexpansive, we see that

$$
\begin{aligned}
\left\|\gamma_{n}-p\right\| & \leq \gamma_{n}\left\|J_{r_{n}}\left(x_{n}-r_{n} A x_{n}\right)-p\right\|+\left(1-\gamma_{n}\right)\left\|J_{s_{n}}\left(x_{n}-s_{n} B x_{n}\right)-p\right\| \\
& \leq\left\|x_{n}-p\right\| .
\end{aligned}
$$

Since $S_{n}$ is nonexpansive, we see that

$$
\begin{aligned}
\left\|x_{n+1}-p\right\| \mid & \leq \alpha_{n}\left\|x_{n}-p\right\|+\left(1-\alpha_{n}\right)\left\|S_{n} y_{n}-p\right\| \\
& \leq \alpha_{n}\left\|x_{n}-p\right\|+\left(1-\alpha_{n}\right)\left\|y_{n}-p\right\| \\
& \leq\left\|x_{n}-p\right\| .
\end{aligned}
$$

Hence, the limit of the sequence $\left\{\left\|x_{n}-p\right\|\right\}$ exists. This shows that the sequence $\left\{x_{n}\right\}$ is bounded, so is $\left\{y_{n}\right\}$. Without loss of generality, we may assume that $\lim _{n \rightarrow \infty}\left\|x_{n}-p\right\|$ $=d>0$. Notice that

$$
\begin{aligned}
\left\|y_{n}-p\right\|^{2} \leq & \gamma_{n}\left\|J_{r_{n}}\left(x_{n}-r_{n} A x_{n}\right)-p\right\|^{2}+\left(1-\gamma_{n}\right)\left\|J_{s_{n}}\left(x_{n}-s_{n} B x_{n}\right)-p\right\|^{2} \\
\leq & \gamma_{n}\left\|\left(x_{n}-r_{n} A x_{n}\right)-p\right\|^{2}+\left(1-\gamma_{n}\right)\left\|\left(x_{n}-s_{n} B x_{n}\right)-p\right\|^{2} \\
\leq & \gamma_{n}\left(\left\|x_{n}-p\right\|^{2}-r_{n}\left(2 \alpha-r_{n}\right)\left\|A x_{n}-A p\right\|^{2}\right) \\
& +\left(1-\gamma_{n}\right)\left(\left\|x_{n}-p\right\|^{2}-s_{n}\left(2 \beta-s_{n}\right)\left\|B x_{n}-B p\right\|^{2}\right) \\
\leq & \left\|x_{n}-p\right\|^{2}-r_{n} \gamma_{n}\left(2 \alpha-r_{n}\right)\left\|A x_{n}-A p\right\|^{2} \\
& -s_{n}\left(1-\gamma_{n}\right)\left(2 \beta-s_{n}\right)\left\|B x_{n}-B p\right\|^{2} .
\end{aligned}
$$


This in turn implies that

$$
\begin{aligned}
\left\|x_{n+1}-p\right\|^{2} \leq & \alpha_{n}\left\|x_{n}-p\right\|^{2}+\left(1-\alpha_{n}\right)\left\|S_{n} y_{n}-p\right\|^{2} \\
\leq & \alpha_{n}\left\|x_{n}-p\right\|^{2}+\left(1-\alpha_{n}\right)\left\|y_{n}-p\right\|^{2} \\
\leq & \left\|x_{n}-p\right\|^{2}-\left(1-\alpha_{n}\right) r_{n} \gamma_{n}\left(2 \alpha-r_{n}\right)\left\|A x_{n}-A p\right\|^{2} \\
& -\left(1-\alpha_{n}\right) s_{n}\left(1-\gamma_{n}\right)\left(2 \beta-s_{n}\right)\left\|B x_{n}-B p\right\|^{2} .
\end{aligned}
$$

It follows from the restrictions (a) and (b) that

$$
(1-i) a j(2 \alpha-b)\left\|A x_{n}-A p\right\|^{2} \leq\left\|x_{n}-p\right\|^{2}-\left\|x_{n+1}-p\right\|^{2} .
$$

Since $\lim _{n \rightarrow \infty}|| x_{n}-p \|=d$, we see that

$$
\lim _{n \rightarrow \infty}\left\|A x_{n}-A p\right\|=0 .
$$

In view of (2.2), we see from the restrictions (a) and (b) that

$$
(1-i) c(1-k)(2 \beta-d)\left\|B x_{n}-B p\right\|^{2} \leq\left\|x_{n}-p\right\|^{2}-\left\|x_{n+1}-p\right\|^{2} .
$$

Since $\lim _{n \rightarrow \infty}|| x_{n}-p||=d$, we see that

$$
\lim _{n \rightarrow \infty}\left\|B x_{n}-B p\right\|=0 .
$$

Notice that $J_{r_{n}}$ is firmly nonexpansive. Putting $u_{n}=J_{r_{n}}\left(x_{n}-r_{n} A x_{n}\right)$ and $v_{n}=J_{s_{n}}\left(x_{n}-s_{n} B x_{n}\right)$, we see that

$$
\begin{aligned}
\left\|u_{n}-p\right\|^{2}= & \left\|J_{r_{n}}\left(x_{n}-r_{n} A x_{n}\right)-J_{r_{n}}\left(p-r_{n} A p\right)\right\|^{2} \\
\leq & \left\langle u_{n}-p,\left(x_{n}-r_{n} A x_{n}\right)-\left(p-r_{n} A p\right)\right\rangle \\
= & \frac{1}{2}\left(\left\|u_{n}-p\right\|^{2}+\left\|\left(x_{n}-r_{n} A x_{n}\right)-\left(p-r_{n} A p\right)\right\|^{2}\right. \\
& \left.-\left\|\left(u_{n}-p\right)-\left(\left(x_{n}-r_{n} A x_{n}\right)-\left(p-r_{n} A p\right)\right)\right\|^{2}\right) \\
\leq & \frac{1}{2}\left(\left\|u_{n}-p\right\|^{2}+\left\|x_{n}-p\right\|^{2}-\left\|u_{n}-x_{n}+r_{n}\left(A x_{n}-A p\right)\right\|^{2}\right) \\
= & \frac{1}{2}\left(\left\|u_{n}-p\right\|^{2}+\left\|x_{n}-p\right\|^{2}-\left\|u_{n}-x_{n}\right\|^{2}-r_{n}^{2}\left\|A x_{n}-A p\right\|^{2}\right. \\
& \left.-2 r_{n}\left\langle u_{n}-x_{n}, A x_{n}-A p\right\rangle\right) \\
\leq & \frac{1}{2}\left(\left\|u_{n}-p\right\|^{2}+\left\|x_{n}-p\right\|^{2}-\left\|u_{n}-x_{n}\right\|^{2}+2 r_{n}\left\|u_{n}-x_{n}\right\|\left\|A x_{n}-A p\right\|\right) .
\end{aligned}
$$

This in turn implies that

$$
\left\|u_{n}-p\right\|^{2} \leq\left\|x_{n}-p\right\|^{2}-\left\|u_{n}-x_{n}\right\|^{2}+2 r_{n}\left\|u_{n}-x_{n}\right\|\left\|A x_{n}-A p\right\| .
$$

In a similar way, we can obtain that

$$
\left\|v_{n}-p\right\|^{2} \leq\left\|x_{n}-p\right\|^{2}-\left\|v_{n}-x_{n}\right\|^{2}+2 s_{n}\left\|v_{n}-x_{n}\right\|\left\|B x_{n}-B p\right\| .
$$


Combining (2.5) with (2.6) yields that

$$
\begin{aligned}
\left\|x_{n+1}-p\right\|^{2} \leq & \alpha_{n}\left\|x_{n}-p\right\|^{2}+\left(1-\alpha_{n}\right)\left\|S_{n} y_{n}-p\right\|^{2} \\
\leq & \alpha_{n}\left\|x_{n}-p\right\|^{2}+\left(1-\alpha_{n}\right)\left\|\gamma_{n}-p\right\|^{2} \\
\leq & \alpha_{n}\left\|x_{n}-p\right\|^{2}+\left(1-\alpha_{n}\right)\left(\gamma_{n}\left\|u_{n}-p\right\|^{2}+\left(1-\gamma_{n}\right)\left\|v_{n}-p\right\|^{2}\right) \\
\leq & \left\|x_{n}-p\right\|^{2}-\left(1-\alpha_{n}\right) \gamma_{n}\left\|u_{n}-x_{n}\right\|^{2}+2 r_{n}\left\|u_{n}-x_{n}\right\|\left\|A x_{n}-A p\right\| \\
& -\left(1-\alpha_{n}\right)\left(1-\gamma_{n}\right)\left\|v_{n}-x_{n}\right\|^{2}+2 s_{n}\left\|v_{n}-x_{n}\right\|\left\|B x_{n}-B p\right\| .
\end{aligned}
$$

It follows that

$$
\begin{aligned}
\left(1-\alpha_{n}\right) \gamma_{n}\left\|u_{n}-x_{n}\right\|^{2} \leq & \left\|x_{n}-p\right\|^{2}-\left\|x_{n+1}-p\right\|^{2}+2 r_{n}\left\|u_{n}-x_{n}\right\|\left\|A x_{n}-A p\right\| \\
& +2 s_{n}\left\|v_{n}-x_{n}\right\|\left\|B x_{n}-B p\right\| .
\end{aligned}
$$

In view of (2.3) and (2.4), we see from the restrictions (a) and (b) that

$$
\lim _{n \rightarrow \infty}\left\|u_{n}-x_{n}\right\|=0
$$

It also follows from (2.7) that

$$
\begin{aligned}
\left(1-\alpha_{n}\right)\left(1-\gamma_{n}\right)\left\|v_{n}-x_{n}\right\|^{2} \leq & \left\|x_{n}-p\right\|^{2}-\left\|x_{n+1}-p\right\|^{2}+2 r_{n}\left\|u_{n}-x_{n}\right\|\left\|A x_{n}-A p\right\| \\
& +2 s_{n}\left\|v_{n}-x_{n}\right\|\left\|B x_{n}-B p\right\| .
\end{aligned}
$$

In view of (2.3) and (2.4), we see from the restrictions (a) and (b) that

$$
\lim _{n \rightarrow \infty}\left\|v_{n}-x_{n}\right\|=0
$$

Notice that

$$
\left\|y_{n}-x_{n}\right\| \leq\left\|u_{n}-x_{n}\right\|+\left\|v_{n}-x_{n}\right\|
$$

It follows from (2.8) and (2.9) that

$$
\lim _{n \rightarrow \infty}\left\|y_{n}-x_{n}\right\|=0
$$

On the other hand, we have

$$
\lim _{n \rightarrow \infty}\left\|\alpha_{n}\left(x_{n}-p\right)+\left(1-\alpha_{n}\right)\left(S_{n} y_{n}-p\right)\right\|=d
$$

Notice that

$$
\left\|S_{n} y_{n}-p\right\| \leq\left\|y_{n}-p\right\| \leq\left\|x_{n}-p\right\| .
$$

This implies that

$$
\limsup _{n \rightarrow \infty}\left\|S_{n} y_{n}-p\right\| \leq d
$$

In view of Lemma 1.5, we arrive at

$$
\lim _{n \rightarrow \infty}\left\|S_{n} y_{n}-x_{n}\right\|=0 .
$$


Note that

$$
S y_{n}-x_{n}=\frac{S_{n} y_{n}-x_{n}}{1-\beta_{n}}+\frac{\beta_{n}\left(x_{n}-y_{n}\right)}{1-\beta_{n}} .
$$

From (2.10), (2.11) and the restriction (b), we get that

$$
\lim _{n \rightarrow \infty}\left\|S y_{n}-x_{n}\right\|=0 \text {. }
$$

On the other hand, we see from Lemma 1.4 that

$$
\begin{aligned}
\left\|S x_{n}-x_{n}\right\| & \leq\left\|S x_{n}-S y_{n}\right\|+\left\|S y_{n}-x_{n}\right\| \\
& \leq \frac{1+\kappa}{1-\kappa}\left\|x_{n}-y_{n}\right\|+\left\|S y_{n}-x_{n}\right\| .
\end{aligned}
$$

It follows from (2.10) and (2.12) that

$$
\lim _{n \rightarrow \infty}\left\|S x_{n}-x_{n}\right\|=0 .
$$

Since $\left\{x_{n}\right\}$ is bounded, we see that there exists a subsequence $\left\{x_{n_{i}}\right\}$ of $\left\{x_{n}\right\}$ which converges weakly to $\bar{x}$. By virtue of Lemma 1.4 , we obtain that $\bar{x} \in F(S)$. Next, we show that $\bar{x} \in(A+M)^{-1}(0)$. Notice that

$$
x_{n}-r_{n} A x_{n} \in u_{n}+r_{n} M u_{n} .
$$

Let $\mu \in M v$. Since $M$ is monotone, we have

$$
\left\langle\frac{x_{n}-u_{n}}{r_{n}}-A x_{n}-\mu, u_{n}-v\right\rangle \geq 0 .
$$

In view of the restriction (a), we see from (2.8) that

$$
\langle-A \bar{x}-\mu, \bar{x}-v\rangle \geq 0 .
$$

This implies that $-A \bar{x} \in M \bar{x}$, that is, $\bar{x} \in(A+M)^{-1}(0)$. In a similar way, we can obtain that $\bar{x} \in(B+W)^{-1}(0)$. This proves that $\bar{x} \in \mathcal{F}$.

Assume that there exists another subsequence $\left\{x_{n_{j}}\right\}$ of $\left\{x_{n}\right\}$ such that $\left\{x_{n_{j}}\right\}$ converges weakly to $x^{\prime}$. By the above proof, we also have $x^{\prime} \in \mathcal{F}$. If $\bar{x} \neq x^{\prime}$, we get from Lemma 1.8 that

$$
\begin{aligned}
\lim _{n \rightarrow \infty}\left\|x_{n}-\bar{x}\right\| & =\liminf _{i \rightarrow \infty}\left\|x_{n_{i}}-\bar{x}\right\|<\liminf _{i \rightarrow \infty}\left\|x_{n_{i}}-x^{\prime}\right\| \\
& =\lim _{n \rightarrow \infty}\left\|x_{n}-x^{\prime}\right\|=\liminf _{j \rightarrow \infty}\left\|x_{n_{j}}-x^{\prime}\right\| \\
& <\liminf _{j \rightarrow \infty}\left\|x_{n_{j}}-\bar{x}\right\|=\lim _{n \rightarrow \infty}\left\|x_{n}-\bar{x}\right\| .
\end{aligned}
$$

This derives a contradiction. Hence, we have $\bar{x}=x^{\prime}$. This implies that $x_{n} \rightarrow \bar{x} \in \mathcal{F}$. Let $e_{n}=P_{\mathcal{F}} x_{n}$. In view of (2.1), we obtain from Lemma 1.6 that $\left\{e_{n}\right\}$ converges strongly to some $e \in \mathcal{F}$. On the other hand, we see from $\bar{x} \in \mathcal{F}$ that $\left\langle x_{n}-e_{n}, e_{n}-\bar{x}\right\rangle \geq 0$. Note that $\left\{x_{n}\right\}$ converges weakly to $\bar{x}$. It follows that

$$
\langle\bar{x}-e, e-\bar{x}\rangle \geq 0 \text {. }
$$

This implies that $\bar{x}=e=\lim _{n \rightarrow \infty} P_{\mathcal{F}} x_{n}$. The proof is completed 
From Theorem 2.1, we can obtain the following immediately.

Theorem 2.2. Let $C$ be a nonempty closed convex subset of a real Hilbert space $H$. Let $S: C \rightarrow C$ be a $\kappa$-strict pseudocontraction, $A_{m}: C \rightarrow H$ be an $\alpha_{m}$-inverse strongly monotone mapping and $M_{m}: H \rightarrow 2^{H}$ be a maximal monotone operator such that $D$ $\left(M_{m}\right) \subset C$, where $m \in\{1, \quad 2, \quad \ldots, \quad K\}$. Assume that $\mathcal{F}:=F(S) \cap \bigcap_{m=1}^{N}\left(A_{m}+M_{m}\right)^{-1}(0) \neq \emptyset$. Let $\left\{x_{n}\right\}$ be a sequence generated in the following manner:

$$
\left\{\begin{array}{l}
x_{0} \in C \\
y_{n}=\sum_{m=1}^{K} \gamma_{n, m} J_{r_{n}, m}\left(x_{n}-r_{n, m} A_{m} x_{n}\right) \\
x_{n+1}=\alpha_{n} x_{n}+\left(1-\alpha_{n}\right)\left(\beta_{n} y_{n}+\left(1-\beta_{n}\right) S y_{n}\right), n \geq 0
\end{array}\right.
$$

where $J_{r_{n}, m}=\left(I+r_{n, m} M_{m}\right)^{-1},\left\{r_{n, m}\right\}$ is a sequence in $\left(0,2 \alpha_{m}\right),\left\{\alpha_{n}\right\},\left\{\beta_{n}\right\}$, and $\left\{\gamma_{n, m}\right\}$ are sequences in $(0,1)$. Assume that the following restrictions are satisfied

(a) $0<a_{m} \leq r_{n, m} \leq b_{m}<2 \alpha_{m}$ for each $m \in\{1,2, \ldots, K\}$;

(b) $\sum_{m=1}^{K} \gamma_{n, m}=1$;

(c) $0 \leq k \leq \beta_{n}<c<1,0<d \leq \alpha_{n} \leq e<1$ and $0<h_{m} \leq \gamma_{n, m} \leq i_{m}<1$, where $a_{1}, a_{2}, \ldots$, $a_{K}, b_{1}, b_{2}, \ldots, b_{K}, c, d, e, h_{1}, h_{2}, \ldots, h_{K}, i_{1}, i_{2}, \ldots, i_{K}$ are real numbers. Then the sequence $\left\{x_{n}\right\}$ converges weakly to $\bar{x} \in \mathcal{F}$, where $\bar{x}=\lim _{n \rightarrow \infty} P_{\mathcal{F}} x_{n}$.

If $S=I$, where $I$ denotes the identity, then Theorem 2.2 is reduced to the following. Corollary 2.3. Let $C$ be a nonempty closed convex subset of a real Hilbert space $H$. Let $A_{m}: C \rightarrow H$ be an $\alpha_{m}$-inverse strongly monotone mapping and $M_{m}: H \rightarrow 2^{H}$ be a maximal monotone operator such that $D\left(M_{m}\right) \subset C$, where $m \in\{1,2, \ldots, K\}$. Assume that $\mathcal{F}:=\bigcap_{m=1}^{N}\left(A_{m}+M_{m}\right)^{-1}(0) \neq \emptyset$. Let $\left\{x_{n}\right\}$ be a sequence generated in the following manner:

$$
x_{0} \in C, \quad x_{n+1}=\alpha_{n} x_{n}+\left(1-\alpha_{n}\right) \sum_{m=1}^{K} \gamma_{n, m} J_{r_{n}, m}\left(x_{n}-r_{n, m} A_{m} x_{n}\right), \quad n \geq 0
$$

where $J_{r_{n}, m}=\left(I+r_{n, m} M_{m}\right)^{-1},\left\{r_{n, m}\right\}$ is a sequence in $\left(0,2 \alpha_{m}\right)$ and $\left\{\alpha_{n}\right\},\left\{\beta_{n}\right\}$ and $\left\{\gamma_{n}\right.$, $m\}$ are sequences in $(0,1)$. Assume that the following restrictions are satisfied

(a) $0<a_{m} \leq r_{n, m} \leq b_{m}<2 \alpha_{m}$ for each $m \in\{1,2, \ldots, K\}$;

(b) $\sum_{m=1}^{K} \gamma_{n, m}=1$;

(c) $0<c \leq \alpha_{n}<d<1$ and $0<h_{m} \leq \gamma_{n, m} \leq i_{m}<1$,

where $a_{1}, a_{2}, \ldots, a_{K}, b_{1}, b_{2}, \ldots, b_{K}, c, d, h_{1}, h_{2}, \ldots, h_{K}, i_{1}, i_{2}, \ldots, i_{K}$ are real numbers. Then the sequence $\left\{x_{n}\right\}$ converges weakly to $\bar{x} \in \mathcal{F}$, where $\bar{x}=\lim _{n \rightarrow \infty} P_{\mathcal{F}} x_{n}$.

\section{Applications}

Let $H$ be a Hilbert space and $f: H \rightarrow(-\infty,+\infty]$ a proper convex lower semicontinuous function. Then the subdifferential $\partial f$ of $f$ is defined as follows: 


$$
\partial f(x)=\{y \in H: f(z) \geq f(x)+\langle z-x, y\rangle, z \in H\}, \forall x \in H .
$$

From Rockafellar $[9,30]$, we know that $\partial f$ is maximal monotone. It is easy to verify that $0 \in \partial f(x)$ if and only if $f(x)=\min _{y \in H} f(y)$.

First, we consider the problem of finding common minimizers of proper convex lower semicontinuous functions.

Theorem 3.1. Let $H$ be a real Hilbert space. Let $f: H \rightarrow(-\infty,+\infty]$ and $g: H \rightarrow(-\infty$, $+\infty]$ be proper convex lower semi-continuous functions. Assume that $\mathcal{F}:=(\partial f)^{-1}(0) \cap(\partial g)^{-1}(0) \neq \emptyset$. Let $\left\{x_{n}\right\}$ be a sequence generated in the following manner:

$$
\left\{\begin{array}{l}
x_{0} \in H \\
z_{n}=\arg \min _{z \in H}\left\{g(z)+\frac{\left\|z-x_{n}\right\|^{2}}{2 s_{n}}\right\}, \\
y_{n}=\arg \min _{z \in H}\left\{f(z)+\frac{\left\|z-x_{n}\right\|^{2}}{2 r_{n}}\right\}, \\
x_{n+1}=\alpha_{n} x_{n}+\left(1-\alpha_{n}\right)\left(\gamma_{n} y_{n}+\left(1-\gamma_{n}\right) z_{n}\right), n \geq 0,
\end{array}\right.
$$

where $\left\{\alpha_{n}\right\},\left\{\beta_{n}\right\}$, and $\left\{\gamma_{n}\right\}$ are sequences in $(0,1)$. Assume that the following restrictions are satisfied

(a) $0<a \leq r_{n} \leq b<\infty$ and $0<c \leq s_{n} \leq d<\infty$;

(b) $0<h \leq \alpha_{n} \leq i<1$ and $0<j \leq \gamma_{n} \leq k<1$,

where $a, b, c, d, h, i, j, k$ are real numbers. Then the sequence $\left\{x_{n}\right\}$ converges weakly to $\bar{x} \in \mathcal{F}$, where $\bar{x}=\lim _{n \rightarrow \infty} P_{\mathcal{F}} x_{n}$.

Proof. Putting $A=B=0$ and $S=I$, the identity mapping, we can conclude from Theorem 2.1 the desired conclusion immediately.

Let $I_{C}$ be the indicator function of $C$, i.e.,

$$
I_{C}(x)=\left\{\begin{aligned}
0, & x \in C \\
+\infty, & x \notin C
\end{aligned}\right.
$$

Since $I_{C}$ is a proper lower semicontinuous convex function on $H$, we see that the subdifferential $\partial I_{C}$ of $I_{C}$ is a maximal monotone operator.

Lemma 3.2. [12] Let $C$ be a nonempty closed convex subset of a real Hilbert space $H$. Let $P_{C}$ be the metric projection from $H$ onto $C, \partial I_{C}$ be the subdifferential of $I_{C}$, where $I_{C}$ is as defined in (3.1) and $J_{r}=\left(I+r \partial I_{C}\right)^{-1}$. Then

$$
y=J_{r} x \Leftrightarrow y=P_{C} x, x \in H, y \in C .
$$

Second, we consider the variation inequality (1.1).

Theorem 3.3. Let $C$ be a nonempty closed convex subset of a real Hilbert space $H$ and $P_{C}$ be the metric projection from $H$ onto $C$. Let $S: C \rightarrow C$ be a $\kappa$-strict pseudocontraction, $A: C \rightarrow H$ be an $\alpha$-inverse strongly monotone mapping and $B: C \rightarrow H$ be a $\beta$-inverse strongly monotone mapping. Assume that $\mathcal{F}:=F(S) \cap \operatorname{VI}(C, A) \cap \operatorname{VI}(C, B) \neq \emptyset$. Let $\left\{x_{n}\right\}$ be a sequence generated in the following manner: 


$$
\left\{\begin{array}{l}
x_{0} \in C^{\prime} \\
y_{n}=\gamma_{n} P_{C}\left(x_{n}-r_{n} A x_{n}\right)+\left(1-\gamma_{n}\right) P_{C}\left(x_{n}-s_{n} B x_{n}\right), \\
x_{n+1}=\alpha_{n} x_{n}+\left(1-\alpha_{n}\right)\left(\beta_{n} y_{n}+\left(1-\beta_{n}\right) S y_{n}\right), \quad n \geq 0
\end{array}\right.
$$

where $\left\{r_{n}\right\}$ is a sequence in $(0,2 \alpha),\left\{s_{n}\right\}$ is a sequence in $(0,2 \beta)$ and $\left\{\alpha_{n}\right\},\left\{\beta_{n}\right\}$ and $\left\{\gamma_{n}\right\}$ are sequences in $(0,1)$. Assume that the following restrictions are satisfied

(a) $0<a \leq r_{n} \leq b<2 \alpha$ and $0<c \leq s_{n} \leq d<2 \beta$;

(b) $0 \leq \kappa \leq \beta_{n}<e<1,0<h \leq \alpha_{n} \leq i<1$ and $0<j \leq \gamma_{n} \leq k<1$,

where $a, b, c, d, e, h, i, j, k$ are real numbers. Then the sequence $\left\{x_{n}\right\}$ converges weakly to $\bar{x} \in \mathcal{F}$, where $\bar{x}=\lim _{n \rightarrow \infty} P_{\mathcal{F}} x_{n}$.

Proof. Put $M=W=\partial I_{C}$. Next, we show that $V I(C, A)=\left(A+\partial I_{C}\right)^{-1}(0)$ and $V I(C, B)$ $=\left(B+\partial I_{C}\right)^{-1}(0)$, respectively. Notice that

$$
\begin{aligned}
x \in\left(A+\partial I_{C}\right)^{-1}(0) & \Leftrightarrow 0 \in A x+\partial I_{C} x \\
& \Leftrightarrow-A x \in \partial I_{C} x \\
& \Leftrightarrow\langle A x, y-x\rangle \geq 0 \\
& \Leftrightarrow x \in V I(C, A)
\end{aligned}
$$

In the same way, we can obtain that $x \in\left(B+\partial I_{C}\right)^{-1} \Leftrightarrow(0) x \in V I(C, B)$. From Lemma 3.2, we can conclude the desired conclusion immediately. $\square$

Remark 3.1. Let $S$ be a nonexpansive mapping, $A=B, M=W$ and $\beta_{n}=0$ in Theorem 3.3. Then Theorem 3.3 is reduced to Theorem 1.1 in Section 1.

Third, we consider the problem of finding common fixed points of three strict pseudocontractions.

Theorem 3.4. Let $C$ be a nonempty closed convex subset of a real Hilbert space $H$. Let $S: C \rightarrow C$ be a $\kappa$-strict pseudocontraction, $T: C \rightarrow C$ be an $\alpha$-strict pseudocontraction and $R: C \rightarrow C$ be a $\beta$-strict pseudocontraction. Assume that $\mathcal{F}:=F(R) \cap F(S) \cap F(T) \neq \emptyset$. Let $\left\{x_{n}\right\}$ be a sequence generated in the following manner:

$$
\left\{\begin{array}{l}
x_{0} \in C \\
y_{n}=\gamma_{n}\left(\left(1-r_{n}\right) x_{n}+r_{n} T x_{n}\right)+\left(1-\gamma_{n}\right)\left(\left(1-s_{n}\right) x_{n}+s_{n} R x_{n}\right), \\
x_{n+1}=\alpha_{n} x_{n}+\left(1-\alpha_{n}\right)\left(\beta_{n} y_{n}+\left(1-\beta_{n}\right) S y_{n}\right), n \geq 0
\end{array}\right.
$$

where $\left\{r_{n}\right\}$ is a sequence in $(0,1-\alpha),\left\{s_{n}\right\}$ is a sequence in $(0,1-\beta)$ and $\left\{\alpha_{n}\right\},\left\{\beta_{n}\right\}$ and $\left\{\gamma_{n}\right\}$ are sequences in $(0,1)$. Assume that the following restrictions are satisfied

(a) $0<a \leq r_{n} \leq b<1-\alpha$ and $0<c \leq s_{n} \leq d<1-\beta$;

(b) $0 \leq \kappa \leq \beta_{n}<e<1,0<h \leq \alpha_{n} \leq i<1$ and $0<j \leq \gamma_{n} \leq k<1$,

where $a, b, c, d, e, h, i, j, k$ are real numbers. Then the sequence $\left\{x_{n}\right\}$ converges weakly to $\bar{x} \in \mathcal{F}$, where $\bar{x}=\lim _{n \rightarrow \infty} P_{\mathcal{F}} x_{n}$.

Proof. Putting $A=I-T$, we see that $A$ is $\frac{1-\alpha}{2}$-inverse-strongly monotone. We also have $F(T)=V I(C, A)$ and $P_{C}\left(x_{n}-r_{n} A x_{n}\right)=\left(1-r_{n}\right) x_{n}+r_{n} T x_{n}$. Putting $B=I-R$, we see that $B$ is $\frac{1-\beta}{2}$-inverse-strongly monotone. We also have $F(R)=V I(C, B)$ and $P_{C}$ 
$\left(x_{n}-s_{n} B x_{n}\right)=\left(1-s_{n}\right) x_{n}+s_{n} R u_{n}$. In view of Theorem 3.2, we can obtain the desired result immediately.

The following lemma can be found in [31,32].

Lemma 3.5. Let $C$ be a nonempty closed convex subset of a real Hilbert space $H$ and let $F$ be a bifunction from $C \times C$ to $\mathbb{R}$ which satisfies $(A 1)-(A 4)$. Then, for any $r>0$ and $x\lfloor H$, there exists $\not$ \& $C$ such that

$$
F(z, y)+\frac{1}{r}\langle y-z, z-x\rangle \geq 0, \quad \forall y \in C
$$

Further, define

$$
T_{r} x=\left\{z \in C: F(z, y)+\frac{1}{r}\langle y-z, z-x\rangle \geq 0, \forall y \in C\right\}
$$

for all $r>0$ and $x \in H$. Then, the following hold:

(a) $T_{r}$ is single-valued;

(b) $T_{r}$ is firmly nonexpansive, i.e., for any $x, y \in H$.,

$$
\left\|T_{r} x-T_{r} y\right\|^{2} \leq\left\langle T_{r} x-T_{r} y, x-y\right\rangle ;
$$

(c) $F\left(T_{r}\right)=E P(F)$;

(d) EP $(F)$ is closed and convex.

Lemma 3.6. [12]Let $C$ be a nonempty closed convex subset of a real Hilbert space $H$. Let $F$ be a bifunction from $C \times C$ to $\mathbb{R}$ which satisfies $(A 1)-(A 4)$ and $A_{F}$ be a multivalued mapping from $H$ into itself defined by

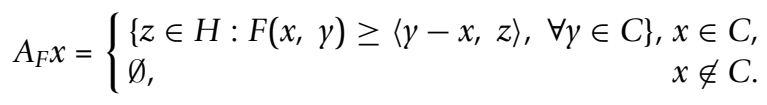

Then $A_{F}$ is a maximal monotone operator with the domain $T_{r} x=\left(I+r A_{F}\right)^{-1} x, \forall x \in H, r>0$, and

$$
T_{r} x=\left(I+r A_{F}\right)^{-1} x, \forall x \in H, r>0,
$$

where $T_{r}$ is defined as in (3.2).

Finally, we consider the problem of finding common elements in solution set of equilibrium problems and in the fixed point set of strict pseudocontractions.

Theorem 3.7. Let $C$ be a nonempty closed convex subset of a real Hilbert space $H$. Let $F$ be a bifunction from $C \times C$ to $\mathbb{R}$ which satisfies (A1)-(A4), G be a bifunction from $C \times C$ to $\mathbb{R}$ which satisfies (A1)-(A4) and $S: C \rightarrow C$ be a $\kappa$-strict pseudocontraction. Assume that $\mathcal{F}:=F(S) \cap E P(F) \cap E P(G) \neq \emptyset$. Let $\left\{r_{n}\right\}$ and $\left\{s_{n}\right\}$ be two positive sequences and $\left\{\alpha_{n}\right\}$, $\left\{\beta_{n}\right\}$, and $\left\{\gamma_{n}\right\}$ sequences in $(0,1)$. Let $\left\{x_{n}\right\}$ be a sequence generated in the following manner: 


$$
\left\{\begin{array}{l}
x_{0} \in C \\
y_{n}=\gamma_{n} u_{n}+\left(1-\gamma_{n}\right) v_{n} \\
x_{n+1}=\alpha_{n} x_{n}+\left(1-\alpha_{n}\right)\left(\beta_{n} y_{n}+\left(1-\beta_{n}\right) S y_{n}\right), n \geq 0
\end{array}\right.
$$

where $u_{n}$ is such that

$$
F\left(u_{n}, u\right)+\frac{1}{r_{n}}\left\langle u-u_{n}, u_{n}-x_{n}\right\rangle \geq 0, \quad \forall u \in C
$$

and $v_{n}$ is such that

$$
G\left(v_{n}, v\right)+\frac{1}{s_{n}}\left\langle v-v_{n}, v_{n}-x_{n}\right\rangle \geq 0, \quad \forall v \in C .
$$

Assume that the following restrictions are satisfied

(a) $0<a \leq r_{n} \leq b<\infty$ and $0<c \leq s_{n} \leq d<\infty$;

(b) $0 \leq \kappa \leq \beta_{n}<e<1,0<h \leq \alpha_{n} \leq i<1$ and $0<j \leq \gamma_{n} \leq k<1$,

where $a, b, c, d, e, h, i, j, k$ are real numbers. Then the sequence $\left\{x_{n}\right\}$ converges weakly to $\bar{x} \in \mathcal{F}$, where $\bar{x}=\lim _{n \rightarrow \infty} P_{\mathcal{F}} x_{n}$.

Proof. Putting $A=B=0$, we can conclude from Lemma 3.6 the desired conclusion immediately.

Remark 3.2. Let $S$ be a nonexpansive mapping, $F=G$ and $\beta_{n}=0$ in Theorem 3.7. Then Theorem 3.7 is reduced to Theorem 1.2 in Section 1.

\section{Competing interests}

The author declares that they have no competing interests.

Received: 28 October 2011 Accepted: 22 February 2012 Published: 22 February 2012

\section{References}

1. Cho, SY, Kang, SM: Approximation of fixed points of pseudocontraction semigroups based on a viscosity iterative process. Appl Math Lett. 24, 224-228 (2011). doi:10.1016/j.aml.2010.09.008

2. Cho, YJ, Kang, SM, Zhou, H: Approximate proximal point algorithms for finding zeroes of maximal monotone operators in Hilbert spaces. J Inequal Appl 2008 (2008). Article ID 598191

3. liduka, H, Takahashi, W: Strong convergence theorems for nonexpansive mappings and inverse-strongly monotone mappings. Nonlinear Anal. 61, 341-350 (2005). doi:10.1016/j.na.2003.07.023

4. Kang, SM, Cho, SY, Liu, Z: Convergence of iterative sequences for generalized equilibrium problems involving inversestrongly monotone mappings. J Inequal Appl 2010, 16 (2010). Article ID 827082

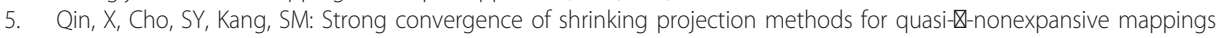
and equilibrium problems. J Comput Appl Math. 234, 750-760 (2010). doi:10.1016/j.cam.2010.01.015

6. Qin, X, Kang, J, Cho, YJ: On quasi-variational inclusions and asymptotically strict pseudo-contractions. J Nonlinear Convex Anal. 11, 441-453 (2010)

7. Qin, X, Kang, SM, Cho, YJ: Approximating zeros of monotone operators by proximal point algorithms. J Glob Optim. 46, 75-87 (2010). doi:10.1007/s10898-009-9410-6

8. Qin, X, Su, Y: Approximation of a zero point of accretive operator in Banach spaces. J Math Anal Appl. 329, 415-424 (2007). doi:10.1016/j.jmaa.2006.06.067

9. Rockafellar, RT: Characterization of the subdifferentials of convex functions. Pac J Math. 17, 497-510 (1966)

10. Rockafellar, RT: On the maximality of sums of nonlinear monotone operators. Trans Am Math Soc. 149, 75-88 (1970). doi:10.1090/S0002-9947-1970-0282272-5

11. Tada, A, Takahashi, W: Weak and strong convergence theorems for a non-expansive mappings and an equilibrium problem. J Optim Theory Appl. 133, 359-370 (2007). doi:10.1007/s10957-007-9187-z

12. Takahashi, S, Takahashi, W, Toyoda, M: Strong convergence theorems for maximal monotone operators with nonlinear mappings in Hilbert spaces. J Optim Theory Appl. 147, 27-41 (2010). doi:10.1007/s10957-010-9713-2

13. Takahashi, W, Toyoda, M: Weak convergence theorems for nonexpansive mappings and monotone mappings. J Optim Theory Appl. 118, 417-428 (2003). doi:10.1023/A:1025407607560

14. Kim, JK, Cho, SY, Qin, X: Hybrid projection algorithms for generalized equilibrium problems and strictly pseudocontractive mappings. J Inequal Appl 2010 (2010). Article ID 312602, 18 
15. Zeng, LC, Ansari, QH, Shyu, SDavid, Yao, JC: Strong and weak convergence theorems for common solutions of generalized equilibrium problems and zeros of maximal monotone operators. Fixed Point Theory Appl 2010 (2010) Article ID 590278

16. Browder, FE, Petryshyn, W: Construction of fixed points of nonlinear mappings in Hilbert space. J Math Anal Appl. 20, 197-228 (1967). doi:10.1016/0022-247X(67)90085-6

17. Marino, G, Xu, HK: Weak and strong convergence theorems for strict pseudo-contractions in Hilbert spaces. J Maht Anal Appl. 329, 336-346 (2007). doi:10.1016/j.jmaa.2006.06.055

18. Jaiboon, C, Kumam, P, Humphries, UW: Weak convergence theorem by an extragradient method for variational inequality, equalibrium and fixed point problems. Bull Malays Math Sci Soc. 32, 131-136 (2009)

19. Kamimura, S, Takahashi, W: Weak and strong convergence of solutions to accretive operator inclusions and applications. Set-Valued Anal. 8, 361-374 (2000). doi:10.1023/A:1026592623460

20. Moudafi, A: Weak convergence theorems for nonexpansive mappings and equilibrium problems. J Nonlinear Convex Anal. 9, 37-43 (2008)

21. Nadezhkina, N, Takahashi, W: Weak convergence theorem by an extragradient method for nonexpansive mappings and monotone mappings. J Optim Theory Appl. 128, 191-201 (2006). doi:10.1007/s10957-005-7564-z

22. Nilsrakooa, W, Saejung, S: Weak and strong convergence theorems for countable Lipschitzian mappings and its applications. Nonlinear Anal. 69, 2695-2708 (2008). doi:10.1016/j.na.2007.08.044

23. Peng, JW, Yao, JC: Weak convergence of an iterative scheme for generalized equilibrium problems. Bull Austral Math Soc. 79, 437-453 (2009). doi:10.1017/S0004972708001378

24. Plubtieng, S, Kumam, P: Weak convergence theorem for monotone mappings and a countable family of nonexpansive mappings. J Comput Appl Math. 224, 614-621 (2009). doi:10.1016/j.cam.2008.05.045

25. Qin, X, Cho, YJ, Kang, SM: Convergence theorems of common elements for equilibrium problems and fixed point problems in Banach spaces. J Comput Appl Math. 225, 20-30 (2009). doi:10.1016/j.cam.2008.06.011

26. Ye, J, Huang, J: Strong convergence theorems for fixed point problems and generalized equilibrium problems of three relatively quasi-nonexpansive mappings in Banach spaces. J Math Comput Sci. 1, 1-18 (2011)

27. Schu, J: Weak and strong convergence of fixed points of asymptotically nonexpansive mappings. Bull Austral Math Soc. 43, 153-159 (1991). doi:10.1017/S0004972700028884

28. Aoyama, K, Kimura, Y, Takahashi, W, Toyoda, M: On a strongly nonexpansive sequence in Hilbert spaces. J Nonlinear Convex Anal. 8, 471-489 (2007)

29. Opial, Z: Weak convergence of the sequence of successive approximation for nonexpansive mappings. Bull Am Math Soc. 73, 591-597 (1967). doi:10.1090/50002-9904-1967-11761-0

30. Rockafellar, RT: Monotone operators and the proximal point algorithm. SIAM J Control Optim. 14, 877-898 (1976). doi:10.1137/0314056

31. Blum, E, Oettli, W: From optimization and variational inequalities to equilibrium problems. Math Stud. 63, 123-145 (1994)

32. Combettes, PL, Hirstoaga, SA: Equilibrium programming in Hilbert spaces. J Nonlinear Convex Anal. 6, 117-136 (2005)

doi:10.1186/1687-1812-2012-21

Cite this article as: Zhang: Iterative algorithms for common elements in fixed point sets and zero point sets with applications. Fixed Point Theory and Applications 2012 2012:21.

\section{Submit your manuscript to a SpringerOpen ${ }^{\odot}$ journal and benefit from:}

- Convenient online submission

- Rigorous peer review

- Immediate publication on acceptance

- Open access: articles freely available online

- High visibility within the field

- Retaining the copyright to your article

Submit your next manuscript at $\gg$ springeropen.com 